\title{
AVALIAÇÃO DE SÓLEOS DE RATAS WISTAR OOFORECTOMIZADAS E REMOBILIZADAS EM MEIO AQUÁTICO
}

ASSESSMENT OF WISTAR RATS SOLEUS OVARIECTOMIZED AND REMOBILIZED IN WATER

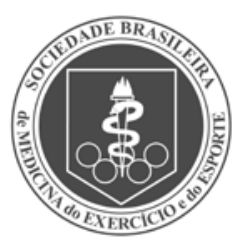

Artigo Original

\section{EVALUACIÓN DE SÓLEOS DE RATAS WISTAR OOFORECTOMIZADAS Y REMOVILIZADAS EN MEDIO ACUÁTICO}

Lígia Inez Silva' (Fisioterapeuta)

Camila Thieime Rosa

(Fisioterapeuta)

Anamaria Meireles' (Fisioterapeuta)

Bruno Pogorzelski Rocha'

(Fisioterapeuta)

Carmen Lúcia Rondon Soares ${ }^{1}$

(Fisioterapeuta)

Lucinéia de Fátima Chasko Ribeiro (Bióloga)

Rose Meire Costa Brancalhão' (Bióloga)

Gladson Ricardo Flor Bertolini'

(Fisioterapeuta)

1. Universidade Estadual do Oeste do Paraná (UNIOESTE), Cascavel, PR, Brasil.

\section{Correspondência:}

Gladson Ricardo Flor Bertolini. Rua Universitária, 2069. Jardim Universitário. Cascavel, Paraná, Brasil. 85819-110.

gladson_ricardo@yahoo.com.br

\section{RESUMO}

Introdução: as incertezas sobre a forma mais eficaz de remobilização para músculos após períodos de imobilização. Objetivo: avaliar o comportamento da remobilização com natação sobre parâmetros histomorfométricos do músculo sóleo de ratas ooforectomizadas e pseudo-ooforectomizadas. Métodos: foram utilizadas 24 ratas Wistar subdivididas em quatro grupos: G1: submetidos à ooforectomia, imobilização por 15 dias e remobilizados livremente; G2: ooforectomia, imobilização e remobilizados com natação por 10 dias; G3: pseudo-ooforectomia, imobilização e remobilizados livremente; G4: pseudo-ooforectomia, imobilização e remobilizados com natação. Os músculos sóleos direitos e esquerdos foram dissecados para as análises histomorfométricas longitudinal e transversal. A contagem de sarcômeros se deu em 300 um e o comprimento da fibra muscular foi medida por paquímetro analógico. O peso muscular foi obtido em balança analítica e o diâmetro foi realizado em 100 fibras por músculo. Resultados: houve redução significativa, tanto na análise longitudinal quanto transversal, quando comparados os músculos sóleos direitos e esquerdos de ambos os grupos. Conclusão: a imobilização do músculo sóleo de ratas ooforectomizadas e pseudo-ooforectomizadas acarreta efeitos deletérios à morfometria muscular e a remobilização por meio da natação não foi capaz de promover o retorno dos padrões estruturais do músculo sóleo.

Palavras-chave: ovariectomia, imobilização, musculoesquelético.

\section{ABSTRACT}

Introduction: uncertainty about the most effective way to muscles remobilization after periods of immobilization. Objective: to evaluate the behavior of swimming remobilization on histomorphometric soleus muscle parameters of ovariectomized rats. Methods: we used 24 Wistar rats divided into four groups: G1: underwent oophorectomy, immobilization for 15 days and remobilized freely; G2: oophorectomy, immobilization and remobilized with swimming for 10 days; G3: pseudo-oophorectomy, immobilization and remobilized freely; G4: pseudo-oophorectomy, immobilization and remobilized with swimming. The right and left soleus muscles were dissected for longitudinal and transverse histomorphometric analysis. The count of sarcomeres occurred at 300 um and muscle fiber length was measured by analog caliper. The muscle weight was obtained in an analytical scale and the diameter was performed on 100 fibers per muscle. Results: there was a significant reduction in both, the longitudinal and transversal analysis, when comparing the right with the left soleus muscles of all groups. Conclusion: the immobilization of the soleus muscle of ovariectomized rats and pseudo-ovariectomized cause deleterious effects on muscle morphology and remobilization through swimming was not able to promote the return of the structural patterns of the soleus muscle.

Keywords: ovariectomy, immobilization, skeletal muscle.

\section{RESUMEN}

Introducción: a la incertidumbre sobre la manera más eficaz de removilización de los músculos después de períodos de inmovilización. Objetivo: Evaluar el comportamiento de removilización con natación sobre parámetros histomorfométricos del músculo sóleo de ratas ooforectomizadas y pseudo ooforectomizadas. Métodos: Se utilizaron 24 ratas Wistar subdivididas en cuatro grupos: G1: sometidas a ooforectomía, inmovilización por 15 días y removilizadas libremente; G2: ooforectomía, inmovilización y removilizadas con natación por 10 días; G3: pseudo ooforectomía, inmovilización y removilizadas libremente; G4: pseudo ooforectomía, inmovilización y removilizadas con natación. Los músculos sóleos derechos e izquierdos fueron disecados para análisis histomorfométricos longitudinal y transversal. El recuento de los sarcómeros se hizo en 300 micras y la longitud de la fibra muscular fue medida por paquímetro analógico. El peso muscular fue obtenido en balanza analítica y el diámetro se realizó en 100 fibras por músculo. Resultados: Hubo reducción significativa tanto en el análisis longitudinal como en el transversal cuando se compararon los músculos sóleos derechos e izquierdos de ambos grupos. Conclusión: La inmovilización del músculo sóleo de ratas ooforectomizadas y pseudo ooforectomizadas 
causa efectos nocivos para la morfometría muscular y la removilización por medio de la natación no fue capaz de promover el retorno de los patrones estructurales del músculo sóleo.

Palabras clave: ooforectomía, inmovilización, músculo esquelético.

\section{INTRODUÇÃO}

O musculoesquelético exibe habilidade de remodelar suas propriedades estruturais e metabólicas em resposta a alterações no ambiente, adaptando-se prontamente. O número de sarcômeros em série varia em resposta à perturbação crônica do comprimento, como em imobilização em posição encurtada ou alongada'. Quando imobilizados em posição de alongamento mostram um aumento do número de sarcômeros em série, atrofia moderada ou ausente, sem mudanças significativas no tecido conjuntivo². Em virtude de tal característica, é considerado o mais mutável dentre os tecidos biológicos, respondendo às demandas com adaptações morfológicas e funcionais ş,4 $^{3,}$

A imobilização acarreta inúmeros efeitos deletérios ao sistema musculoesquelético. Entretanto, caracteriza-se como um dos recursos amplamente utilizado para a reabilitação de lesões. Apenas uma semana é suficiente para promover adaptações e alterações significativas na morfometria e na mecânica dos músculos sóleo e gastrocnêmico de ratos, como redução da massa, comprimento musculares e número de sarcômeros, e aumento da densidade do tecido conjuntivo, com redução da resistência máxima de ruptura muscular ${ }^{5,6}$.

Uma das variáveis que contribui para o grau de adaptação do tecido muscular são os hormônios como o estrógeno. Este tem a capacidade de aumentar a quantidade da reserva de glicogênio no músculo e consequentemente minimizar as alterações metabólicas musculares geradas pela imobilização?

Uma das modalidades utilizadas na reabilitação de músculos imobilizados é a atividade física. Com o exercício físico há ativação de mecanismos de mobilização de substratos energéticos, visando à manutenção do trabalho muscular. O exercício agudo ocasiona alterações que iniciam ajustes orgânicos para procurar manter a homeostasia. Esses ajustes promovem significativa disponibilidade de oxigênio aos órgãos e tecidos envolvidos no exercício, bem como, a liberação de hormônios. Desta forma, o exercício físico possui a capacidade de influenciar na reversão de efeitos deletérios causados pela imobilização $0^{8,9}$.

Embora haja constatação de que os músculos se adaptam sob diferentes formas de estímulos, ainda há incerteza de qual a forma mais eficaz de aplicá-los visando conduzir os músculos hipotrofiados e encurtados ao retorno de sua máxima eficácia, apresentando características morfológicas semelhantes as do período pré-imobilizacão ${ }^{10}$. O objetivo do presente estudo foi avaliar o comportamento da imobilização em posição de encurtamento e da remobilização com natação sobre parâmetros histomorfométricos musculares longitudinais e transversais do músculo sóleo de ratas ooforectomizadas e pseudo-ooforectomizadas.

\section{MATERIAIS E MÉTODOS}

O projeto do estudo foi aprovado pelo Comitê de Ética em Uso de Animais da Universidade Estadual do Oeste do Paraná (UNIOESTE) sob o parecer 02311. Utilizou-se 36 ratas, da linhagem Wistar, com 10 2 semanas de idade, obtidas no Biotério Central da UNIOESTE. Os animais foram mantidos em gaiolas de polipropileno, com ciclo claro/escuro de 12 horas, à $23^{\circ} \mathrm{C} \pm 2^{\circ} \mathrm{C}$, com acesso à água e ração ad libitum. Os animais foram pesados e identificados e em seguida divididos em quatro grupos:
Grupo Pseudo-Ooforectomizado (G1, n=6): os animais deste grupo foram submetidos à pseudo-ooforectomia, permanecendo 60 dias sem intervenção.

Grupo Ooforectomizado (G2, n=6): este grupo foi submetido à ooforectomia, permanecendo 60 dias sem intervenção.

Grupo Ooforectomizado, imobilizado e submetido à remobilização livre $(G 3, n=6)$ : os animais deste grupo foram submetidos à ooforectomia, permanecendo 30 dias sem intervenção. Após esse período os animais tiveram o membro posterior direito imobilizado por 15 dias consecutivos, com intuito de manter o músculo sóleo em posição de encurtamento. Após o período de imobilização realizou-se a remobilização por 10 dias, em que os animais foram colocados em contato com a água e retirados logo em seguida.

Grupo Ooforectomizado, imobilizado e submetido à remobilização com natação (G4, n=6): este grupo foi submetido à ooforectomia, permanecendo 30 dias sem intervenção. Após esse período foi realizada a imobilização, por um período de 15 dias consecutivos. Em seguida, foram submetidos à natação, por 15 min na primeira semana e 30 min na segunda semana.

Grupo Pseudo-Ooforectomizado, imobilizado e submetido à remobilização livre (G5, n=6): os animais foram submetidos à cirurgia simulada de ooforectomia (Pseudo-Ooforectomia), permanecendo 30 dias sem intervenção. Após esse período os animais foram submetidos à imobilização por 15 dias consecutivos. Posteriormente, a remobilização foi realizada por 10 dias, período no qual os animais foram apenas colocados em contato com a água e retirados logo em seguida.

Grupo Pseudo-Ooforectomizado, imobilizado submetido à remobilização com natação $(G 6, n=6)$ : os animais desse grupo foram submetidos à cirurgia simulada de ooforectomia, permanecendo 30 dias sem intervenção. Após esse período foi realizada a imobilização por 15 dias consecutivos. Posteriormente, foram submetidos à natação, por 15 minutos na primeira semana e 30 minutos na segunda semana durante 10 dias.

Os animais foram previamente anestesiados com injeção intraperitoneal de xilazina (10 mg/Kg) e ketamina (75 mg/Kg). Em seguida a região do baixo ventre foi tricotomizada e a antissepsia feita com álcool iodado. A incisão cirúrgica foi feita com lâmina de bisturi e uma pequena sutura com fio reabsorvível catgut 4.0 cromado, posteriormente realizou-se na base uterina a ooforectomia bilateral. Na fase final do procedimento as suturas internas foram feitas com fio reabsorvível e as externas com fio catgut. A pseudo-ooforectomia, consistiu na realização de etapas cirúrgicas semelhantes à ooforectomia, com exceção da remoção dos ovários.

Foi utilizado o protocolo de imobilização readequado para somente um dos membros confeccionado em aparelho gessado ${ }^{11}$. Os animais tiveram a órtese moldada diretamente no seu membro posterior direito, sendo colocada de forma que este permaneceu em extensão de joelho e plantiflexão de tornozelo, ou seja, em posição de encurtamento do músculo sóleo, a mesma foi mantida por 15 dias consecutivos.

Após a retirada da imobilização, os animais do grupo G3 e G5 foram apenas colocados em contato em um tanque com capacidade de 200 litros, circular, com profundidade de $50 \mathrm{~cm}$, a $32 \pm 1^{\circ} \mathrm{C}$, verificadas por termômetro Inconterm $^{\circledR}$, a fim de garantir o mesmo tratamento entre os grupos experimentais, minimizando diferentes respostas de estresse pela ação do contato com a água. Já os animais de G4 e G6, 
foram submetidos à remobilização com natação. Nos primeiros 5 dias, o tempo de natação foi de 15 min, e nos 5 dias restantes, após intervalo de dois dias, o tempo de natação foi de 30 minutos.

Ao final do experimento, todos os animais foram pesados e sofreram eutanásia por decapitação em guilhotina. Logo após, os músculos sóleos direitos (imobilizados) e esquerdos (controle) foram isolados e limpos.

Após a retirada dos músculos, os mesmos foram imersos em formalina 7\%, por 3 h. Posteriormente, foram seccionados longitudinalmente, sendo que as partes laterais foram fixadas em placas de isopor em seu comprimento máximo de repouso. Em seguida foram imersos em ácido nítrico (30\%) por 72 h e armazenados em glicerol (50\%). Posteriormente o sóleo foi colocado em uma placa de Petri, e com o auxílio de lupa (Micronal ${ }^{\circledR}$ ), foram isoladas cinco fibras, de tendão a tendão, com uso de pinças com pontas ultrafinas, e montadas em lâmina histológica envernizadas, ocorrendo a avaliação do comprimento da fibra com uso do paquímetro analógico (Tecnolub $\left.{ }^{\circledR}\right)$. Para a análise do número de sarcômeros utilizou-se microscópio (Olympus ${ }^{\circledR}$ ), com objetiva de 40x, do qual foram captadas imagens das fibras musculares isoladas, e digitalizadas, para análise com o programa Image-Pro-Plus3.0 ${ }^{\circledR}$, com o qual foi feita a contagem dos sarcômeros ao longo de $50 \mu \mathrm{m}$ na imagem, em seis campos não consecutivos (300 $\mu \mathrm{m}$ ). O cálculo utilizado para estimar o total de sarcômeros em série, ao longo da fibra, foi regra de três simples.

Para análise histólógica de caráter transversal utilizou-se a parte medial do músculo sóleo. Os músculos foram fixados em placas de isopor em seu comprimento máximo e imersos em formalina 7\% para fixação das estruturas celulares por 72 horas e em seguida foram transferidos para o álcool a 70\%, permanecendo nessa solução até a preparação das lâminas histológicas. Assim, o material biológico foi desidratado em série crescente de etanol, diafanizado em xilol e impregnado em parafina histológica. Posteriormente, foi à microtomia, com cortes de $7 \mu \mathrm{m}$ e coloração em hematoxilina e eosina. Os campos visuais de interesse foram capturados por meio de microscópio (Olympus ${ }^{\circledR}$ ) com objetiva de 40x e digitalizados para análise no programa Image-Pro-Plus3.0 ${ }^{\circledR}$, quanto à área de secção transversa em 100 fibras por músculo ${ }^{12}$.

\section{Análise Estatística}

Os dados obtidos foram analisados por meio do teste $t$ de Student (para comparação dentro dos grupos) e ANOVA unidirecional (para comparação entre grupos), com pós-teste de Tukey. O nível de significância aceito foi de 5\%.

\section{RESULTADOS}

Na análise longitudinal pode-se observar que houve diferença significativa $(p<0,05)$ em todos os grupos imobilizados, ao comparar o comprimento das fibras musculares e a estimativa de sarcomeros em séries nas fibras dos sóleos direitos (tratados) e esquerdos (controle), sendo que os valores encontrados do lado esquerdo se apresentaram maiores que as do músculo sóleo direito (tabela 1).

Nas comparações entre grupos, não houve diferenças ( $p>0,05)$ quando se comparou os lados direitos, nem os lados esquerdos, para o comprimento das fibras. O mesmo ocorreu para a estimativa de sarcomeros no lado esquerdo ( $p>0,05)$, já para o lado direito houve diferenças, sendo que $\mathrm{G} 1$ e $\mathrm{G} 2$ foram semelhantes entre si ( $p>0,05)$, mas, maiores do que os outros grupos $(p<0,05)$.

Ao comparar a massa muscular e também o diâmetro médio das fibras dos músculos sóleos direitos e esquerdos, observou-se diferença estatisticamente significativa em todos os grupos imobilizados, sendo que as fibras musculares do sóleo direito apresentaram maior hipotrofia com relação às fibras do sóleo esquerdo (tabela 2).
Tabela 1. Valores obtidos na avaliação longitudinal dos sóleos direito e esquerdos, com relação ao comprimento das fibras $(\mathrm{cm})$ e da estimativa de sarcômeros ao longo da fibra, de acordo com os grupos.

\begin{tabular}{c|c|c|c|c|c|c}
\hline & \multicolumn{3}{|c|}{ Comprimento da fibra } & \multicolumn{3}{c}{ Estimativa de sarcômeros } \\
\hline & Esquerdo & Direito & Valor $\mathbf{p}$ & Esquerdo & Direito & Valor $\mathbf{p}$ \\
\hline G1 & $0,801 \pm 0,278$ & $0,949 \pm 0,203$ & 0,2531 & $5606 \pm 1384$ & $6611 \pm 1234$ & 0,1194 \\
\hline G2 & $0,872 \pm 0,381$ & $0,9613 \pm 0,153$ & 0,6907 & $6187 \pm 2570$ & $7200 \pm 511,8$ & 0,3756 \\
\hline G3 & $1,004 \pm 0,125$ & $0,758 \pm 0,116$ & $0,0029^{*}$ & $4505 \pm 473,5$ & $3288 \pm 652,2 \bullet$ & $0,0012^{*}$ \\
\hline G4 & $1,052 \pm 0,034$ & $0,851 \pm 0,121$ & $0,0093^{*}$ & $4955 \pm 187,9$ & $3841 \pm 749,2 \bullet$ & $0,0099^{*}$ \\
\hline G5 & $1,051 \pm 0,038$ & $0,757 \pm 0,056$ & $0,0009^{*}$ & $4738 \pm 161,8$ & $3156 \pm 272,0 \bullet$ & $0,0001^{*}$ \\
\hline G6 & $1,026 \pm 0,073$ & $0,786 \pm 0,099$ & $0,0009^{*}$ & $4563 \pm 406,9$ & $3344 \pm 373,7 \bullet$ & $0,0002^{*}$ \\
\hline
\end{tabular}

* diferença significativa ao comparar com o contralateral. • diferença significativa ao comparar com G1 e G2.

Tabela 2. Valores obtidos na avaliação transversal dos sóleos direito e esquerdos, com relação ao diâmetro das fibras musculares $(\mu \mathrm{m})$, de acordo com os grupos.

\begin{tabular}{c|c|c|c}
\hline & \multicolumn{3}{|c}{ Diâmetro muscular } \\
\hline G1 & Esquerdo & Direito & Valor $\mathbf{p}$ \\
\hline G2 & $30,95 \pm 2,94$ & $32,52 \pm 4,13$ & 0,5322 \\
\hline G3 & $35,43 \pm 2,93$ & $35,40 \pm 4,37$ & 0,9836 \\
\hline G4 & $34,12 \pm 3,83$ & $23,18 \pm 3,31 \cdot$ & $0,0047^{*}$ \\
\hline G5 & $33,21 \pm 2,70$ & $22,98 \pm 6,44 \cdot$ & $0,0070^{*}$ \\
\hline G6 & $31,67 \pm 1,70$ & $23,46 \pm 2,42 \cdot$ & $0,0003^{*}$ \\
\hline * diferença significativa ao comparar com o contralateral. diferença significativa ao comparar com G1 e G2.
\end{tabular}

De forma semelhante ao encontrado para a estimativa de sarcômeros, não houve diferenças $(p>0,05)$ para os diâmetros observados para o lado esquerdo ( $p>0,05)$, mas para o lado direito houve diferenças, apesar de G1 e G2 terem sido semelhantes entre si ( $p>0,05)$, foram maiores do que os outros grupos $(p<0,05)$.

\section{DISCUSSÃO}

No âmbito clínico da reabilitação física, ainda permanecem incertezas sobre o comportamento bem como, reorganização de algumas variáveis do tecido muscular submetido a um período de imobilização e consequente inatividade muscular. De acordo com os resultados obtidos no estudo em questão, pode-se afirmar que, o período de imobilização utilizado no mesmo foi suficiente para acarretar significativas alterações deletérias na morfometria do músculo sóleo de ratas wistar submetidas à ooforectomia e pseudo-ooforectomia, no que tange às variáveis de caráter longitudinal e transversal, tanto na comparação dentro dos grupos, quanto na comparação entre os grupos imobilizados com os dois primeiros (sem imobilização), demonstrando diferenças significativas de caráter hipotrófico para os lados imobilizados. Tais achados corroboram com os resultados obtidos em estudos anteriores ${ }^{13,14}$.

De acordo com Willians e Goldspink ${ }^{15}$, a perda de sarcômeros em série nos músculos imobilizados em posição de encurtamento ocorre principalmente nas primeiras duas semanas após a imobilização. Tabary et al. ${ }^{16}$, observaram que após quatro semanas de imobilização em posição de encurtamento muscular ocorreu diminuição em 40\% do número de sarcômeros em série ao longo da fibra muscular de gatos. No presente estudo, embora o modelo animal tenha sido outro, esse fato também pode ser observado, no qual os grupos submetidos à imobilização apresentaram significava diminuição do número de sarcômeros em série ao longo da fibra muscular, comprovando dados solidificados na literatura a cerca da plasticidade do músculo sóleo.

Após o referido período de duas semanas de imobilização em posição de encurtamento pode-se observar que, os animais obtiveram 
redução acentuada do peso do músculo sóleo direito, relacionando-se positivamente com os resultados encontrados por Kannus et al. ${ }^{17}$, Volpi et al. ${ }^{18}$, e Gomes et al. ${ }^{2}$. Além disso, o processo de imobilização induz a apoptose que acarreta redução no numero de mionúcleos e do conteúdo de DNA, induzindo, por conseguinte, uma atrofia muscular e consequente perda de peso ${ }^{19}$.

Para Lima et al. ${ }^{5}$, o período compreendido de uma semana é suficiente para promover adaptações e alterações na morfometria e na mecânica dos músculos sóleo e gastrocnêmico de ratos tratados. Tais achados confirmam os resultados obtidos por meio das análises histomorfométricas do presente estudo, uma vez que, as fibras musculares do músculo sóleo se comportaram de forma semelhante no sentido longitudinal bem como transversal reduzindo seu trofismo.

A cerca do processo de remobilização, inúmeros estudos relevantes conduzidos nesse contexto de experimentação animal, pautaram-se na observação do comportamento de diferentes formas de remobilização no que tange às propriedades do músculoesquelético de ratos wistar. Segundo Volpi et al. ${ }^{18}$, duas semanas de remobilização por meio da natação, com tipos distintos de sobrecarga não foram capazes de reverter totalmente o processo de atrofia causado pela imobilização.

Em contrapartida, o estudo realizado por Polizello et al. ${ }^{20}$, comprovou que 10 dias de remobilização livre foram capazes de restaurar os valores de propriedades mecânicas após 15 dias de imobilização.

No que tange ao sistema hormonal, Moreira et al. ${ }^{21}$ contextualiza que o estrogênio é de suma importância para os animais do gênero feminino. A supressão da fonte produtora, ou seja, os ovários, ou até mesmo a cessação fisiológica de sua produção, acarreta um processo desestruturador no corpo desses animais. Dessa forma, afirma-se que, o hipoestrogenismo prolongado proporciona subsídios para um processo de perda de densidade no interior da fibra muscular, diminuindo seu sarcoplasma, fato que seria responsável pela perda de espessura, do tônus bem como da força do músculo esquelético, quadro conhecido como sarcopenia22,23.

Moreira et al. ${ }^{21}$ realizaram um estudo histomorfométrico do músculoesquelético em ratas submetidas à suspensão endócrina do estrogênio por castração. Identificaram sarcopenia e redução do número de miofibras do músculoesqueléticos. Os resultados evidenciados no presente estudo contrapõem-se com tais afirmações uma vez que, não foi possível observar diferença significativa entre ooforectomizados e pseudo-ooforectomizados, frente às propriedades histomorfométricas longitudinais e transversais do músculo sóleo, porém, o prazo entre a retirada dos ovários e o início da remobilização podem não ter sido suficientes para maior alteração no músculo esquelético. Salienta-se, ainda, como limitação a falta de análise bioquímica do estrogênio fato que se sugere como tema de futuros estudos.

\section{CONCLUSÃO}

Considerando as variáveis analisadas e a metodologia empregada, conclui-se que a imobilização do músculo sóleo de ratas ooforectomizadas e pseudo-ooforectomizadas acarreta efeitos deletérios à morfometria muscular e nesse contexto a remobilização por meio da natação não foi capaz de gerar estímulos mecânicos suficientes para promover retorno dos padrões estruturais do músculo sóleo.

\section{AGRADECIMENTOS}

Ao Conselho Nacional de Desenvolvimento Científico e Tecnológico (CNPq) e Universidade Estadual do Oeste do Paraná, pela disponibilização de bolsas de Iniciação Científica.

Todos os autores declararam não haver qualquer potencial conflito de interesses referente a este artigo.

\section{REFERÊNCIAS}

1. Shah SB, Peters D, Jordan KA, Milner DJ, Fridén J, Capetanaki Y, et al. Sarcomere number regulation maintained after immobilization in desminnull mouse skeletal muscle. J Exp Biol. 2001;204(10):1703-10.

2. Gomes AR, Coutinho EL, França CN, Polonio J, Salvini TF. Effect of one stretch a week applied to the immobilized soleus muscle on rat muscle fiber morphology. Braz J Med Biol Res. 2004;37(10):1473-80.

3. Ikeda S, Yoshida A, Matayoshi S, Horinouchi K, Tanaka N. Induction of myogenin messenger ribonucleic acid in rat skeletal muscle after 1 hour of passive repetitive stretching. Arch Phys Med Rehabil. 2004:85(1):166-7.

4. Pattison JS, Folk LC, Madsen RW, Booth FW Selected Contribution: Identification of differentially expressed genes between young and old rat soleus muscle during recovery from immobilization-induced atrophy. J Appl Physiol. 2003;95(5):2171-9.

5. Lima SC, Caierão QM, Durigan JLQ, Schwarzenbeck A, Silva CA, Minamoto VB, et al. Curto período de imobilização provoca alterações morfométricas e mecânicas no músculo de rato. Rev Bras Fisioter. 2007;11(4):297-302.

6. da Silva CA, Guirro RR, Polacow ML, Cancelliero KM, Durigan JL. Rat hindlimb joint immobilization with acrylic resin orthoses. Braz J Med Biol Res. 2006;39(7):979-85.

7. Baroni BM, Galvão $A Q$, Ritzel $C H$, Diefenthaeler F, Vaz MA. Adaptações neuromusculares de flexores dorsais e plantares a duas semanas de imobilização após entorse de tornozelo. Rev Bras Med Esporte. 2010;16(5):358-62.

8. Rogatto GP, Oliveira CAM, Faria MC, Luciano E. Respostas metabólicas agudas de ratos Wistar ao exercício intermitente de saltos. Motriz. 2004;10(2):61-6.

9. Afonso M, Souza CN, Zagatto AM, Luciano E. Respostas metabólicas agudas ao exercício físico moderado em ratos Wistar. Motriz. 2003;9(2):83-8.

10. Natali LH, Silva TS, Ciena AP, Padoin MJ, Alves EPB, Aragão FA, et al. Efeitos da corrida em esteira em músculos sóleos de ratos encurtados por imobilização. Rev Bras Med Esporte. 2008;14(6):490-3.

11. Matheus JPC, Gomide LB, Oliveira JGP, Volpon JB, Shimano AC. Efeitos da estimulação elétrica neuromuscular durante a imobilização nas propriedades mecânicas do músculo esquelético. Rev Bras Med Esporte. 2007;13(1):55-9.
12. Brito MKM, Camargo Filho JCS, Vanderlei LCM, Tarumoto MH, Dal Pai V, Giacometti JA. Dimensões geométricas das fibras do músculo sóleo de ratos exercitados em esteira rolante: a importância da análise por meio de imagens digitalizadas, Rev Bras Med Esporte. 2006;12(2):103-7.

13. Bertolini SMMG, Oliveira PD, Cararo DC. Estudo morfométrico do músculo sóleo de ratos da linhagem wistar pós-imobilização articular. Acta Sci Health Sci. 2010;32(1):23-7.

14. Santos-Junior FFU, Alves JSM, Machado AAN, Carlos PS, Ferraz ASM, Barbosa R, et al. Alterações morfométricas em músculo respiratório de ratos submetidos à imobilização de pata. Rev Bras Med Esporte. 2010;16(3):215-8.

15. Willians PE, Goldspink G. Connective tissue changes in immobilised muscle. J Anat. 1984;138(2):343-50.

16. Tabary JC, Tabary C, Tardieu C, Tardieu G, Goldspink G. Physiological and structural changes in the cat's soleus muscle due to immobilization at different lengths by plaster casts. J Physiol. 1972;224(1):231-44

17. Kannus $P$, Jozsa $L$, Järvinen $T L$, Kvist M, Vieno T, Järvinen $T A$, et al. Free mobilization and low- to high-intensity exercise in immobilization-induced muscle atrophy. J Appl Physiol. 1998;84(4):1418-24.

18. Volpi FS, Casarolli LM, Pudell C, Menon T, Ciena AP, Alves ÉPB, et al. Efeitos da remobilização em duas semanas com natação sobre o músculo sóleo de ratos submetidos à imobilização. Rev Bras Med Esporte. 2008;14(3):168-70

19. Mozdziak PE, Pulvermacher PM, Schultz E. Muscle regeneration during hindlimb unloading results in a reduction in muscle size after reloading. J Appl Physiol. 2001;91(1):183-90.

20. Polizello JC, Carvalho LC, Freitas FC, Padula N, Shimano AC, Mattiello-Sverzut AC. Propriedades mecânicas do músculo gastrocnêmio de ratas, imobilizado e posteriormente submetido a diferentes protocolos de alongamento. Rev Bras Med Esporte. 2009;15(3):195-9.

21. Moreira MA, Brito MVH, Brito NMB, Freire Filho MSL. Estudo histomorfométrico do músculo esquelético de ratos em anestro. Acta Cir Bras. 2005;20(4):329-35.

22. Zammit P, Beauchamp J.The skeletal muscle satellite cell: stem cell or son of stem cell? Differentiation 2001;68(4-5):193-204.

23. Tiidus PM, Holden D, Bombardier E, Zajchowski S, Enns D, Belcastro A. Estrogen effect on post-exercise skeletal muscle neutrophil infiltration and calpain activity. Can J Physiol Pharmacol. 2001;79(5):400-6. 